\title{
Monitoramento de variáveis micrometeorológicas em diferentes ambientes protegidos no período de inverno
}

\author{
Rita de Cássia Mariano de Paula ${ }^{1}$, Abimael Gomes da Silva ${ }^{1}$, Edilson $_{\text {Costa }}{ }^{1}$, Flávio Ferreira \\ da Silva Binotti ${ }^{1}$
}

${ }^{1}$ Universidade Estadual de Mato Grosso do Sul, Unidade Universitária de Cassilândia, Cassilândia, Mato Grosso do Sul, Brasil.

E-mail: rcmp92@hotmail.com, maeldruida@hotmail.com, mestrine@uems.br, binotti@uems.br

Recebido: 01/11/2017; Aceito: 01/11/2017.

\section{RESUMO}

Ambientes distintos podem exercer influência sobre o crescimento e desenvolvimento de mudas devido à diferença entre as variáveis micrometeorológicas. Objetivou-se desta forma, monitorar e comparar as variáveis micrometeorológicas no interior de ambientes protegidos, na Universidade Estadual de Mato Grosso do Sul, Unidade Universitária de Cassilândia, MS, no período de 28 de junho a 27 de agosto de 2017. Os ambientes avaliados foram: 1. estufa agrícola coberta com filme de polietileno com tela lateral e frontal de $30 \%$ de sombreamento, com tela termorrefletora aluminizada móvel $(42 / 50 \%)$; 2 . estufa agrícola coberta com filme de polietileno com tela lateral e frontal de $30 \%$ de sombreamento, com tela termorrefletora aluminizada móvel (22/30\%); 3. telado agrícola com tela termorrefletora aluminizada de $35 \%$ de sombreamento; 4 . telado agrícola com tela de monofilamento preta de $30 \%$ de sombreamento; 5 . telado agrícola com tela de monofilamento preta de $18 \%$ de sombreamento; 6 . externo. Os dados de temperatura $\left(\mathrm{T}^{\circ} \mathrm{C}\right)$, umidade relativa (UR\%) e radiação global (RG) foram comparados pelo teste de Tukey a $5 \%$. A T ${ }^{\circ} \mathrm{C}$ e UR\% não diferiram nos ambientes durante o inverno. Os ambientes 1, 2, 3, 4 e 5 reduziram, respectivamente, 71, 61, 49, 49 e $52 \%$ da radiação solar externa disponível no período de inverno.

Palavras-chave: temperatura, umidade, radiação.

\section{Monitoring of micrometeorological variables in different environments protected in the winter period}

\begin{abstract}
Different environments may exert influence on the growth and development of seedlings due to the difference between micrometeorological variables. The objective was to monitor and compare the micrometeorological variables inside protected environments, at UEMS, Cassilândia-MS, Brazil, from June 28 to August 27, 2017. The evaluated environments were: 1) agricultural greenhouse covered with polyethylene film with lateral and frontal screen of $30 \%$ of shading, with thermo-reflective aluminized mobile screen $(42 / 50 \%) ; 2$ ) agricultural stove covered with polyethylene film with side and front $30 \%$ shading, with aluminized thermo-reflective screen mobile $(22 / 30 \%)$; 3) agricultural screen with 35\% aluminized thermo-reflective shading; 4 ) agricultural screen with black monofilament screen of 30\% shading; 5) agricultural screen with black monofilament screen of $18 \%$ shading and 6) external. The data of temperature $\left(\mathrm{T}^{\circ} \mathrm{C}\right)$, relative humidity (UR\%) and global radiation (RG) were compared by the Tukey test at $5 \%$. The $\mathrm{T}^{\circ} \mathrm{C}$ and UR\% did not differ in the environments during the winter. The environments $1,2,3,4$ and 5 reduced, respectively, 71, 61, 49, 49 and 52\% from external radiation in the winter period.
\end{abstract}

Key words: temperature, humidity, radiation. 


\section{Introdução}

Atualmente o cultivo em ambientes protegidos é encontrado em todo território brasileiro. Desde quando se iniciou no Brasil na década de 80 do século passado, essa tecnologia passou por diversas fases de adaptação e cada vez mais os produtores a procuram devido aos resultados alcançados nos quesitos qualidade $\mathrm{e}$ produtividade dos cultivos. Com a possibilidade de se cultivar uma espécie fora dos períodos usuais (CARON et al., 2010), por meio das alterações das variáveis micrometeorológicas no interior dos ambientes, onde se obtêm melhor qualidade dos produtos (CARDOSO et al., 2008; ANDRADE et al., 2011), aliada aos resultados de produtividade comprovadas e excelentes resultados obtidos na fase inicial de crescimento vegetal, a tecnologia de cultivo protegido conseguiu sua consolidação entre os produtores brasileiros.

Muitos produtores utilizavam cobertura plástica para produção de uvas, pois desta maneira minimizavam os efeitos do excesso de chuva ou queda de granizo (CARDOSO et al., 2008), no entanto, o cultivo protegido possibilita também alterações no balanço de energia no interior dos ambientes, e em períodos de elevada disponibilidade energética ameniza a temperatura do vegetal (CARON et al., 2010). Além da proteção contra intempéries e modificações micrometeorológicas (COSTA; LEAL, 2011), é possível alcançar menor incidência de doenças fúngicas em ambientes protegidos (CHAVARIA et al., 2007).

Apesar de, na maioria das vezes, contribuir na melhoria das variáveis micrometeorológicas do ambiente de produção, vale ressaltar que a escolha do ambiente pode interferir positiva ou negativamente na qualidade das plantas (OLIVIERA et al., 2009), por isso, deve-se considerar diversas características das espécies a serem produzidas, relacionadas ao grupo sucessioal, habitat e nicho de cada espécie (CÉSAR et al., 2014).

Os materiais utilizados na cobertura dos ambientes protegidos são variados, mas usualmente utilizam-se filmes de polietileno de baixa densidade, malhas pretas, malhas aluminizadas ou coloridas, com diferentes porcentagens de sombreamento. $\mathrm{O}$ uso de sombreamento no manejo do microclima do ambiente de produção vegetal é uma das técnicas mais simples, a qual implica menores gastos (FERRARI; LEAL, 2015).

Em regiões tropicais a utilização de ambientes do tipo telado promovem a redução da luminosidade (SANTOS et al., 2010), temperatura do ar e do solo (SANTOS et al., 2010; RAMPAZZO et al., 2014), e aumento da umidade relativa do ar (RAMPAZZO et al., 2014), melhorando o desenvolvimento das culturas. A utilização de estufas agrícolas como ambiente de produção vegetal altera a temperatura do ar e do solo, bem como a umidade relativa do ar e radiação solar incidente no interior dos mesmos (BECKMANN et al., 2006). Quando se utiliza o filme de polietileno de baixa densidade, com ou sem difusor de luz, com ou sem antigotejamento, se altera o balanço energético nos ambientes de cultivo (CUNHA et al., 2002), pois os filmes apresentam aditivos que alteram a radiação solar, alterando, consequentemente as temperaturas internas (SOUSA et al., 2002).

A radiação solar global $(\mathrm{Rg})$ é a principal fonte de energia disponível para a realização de diversos processos atmosféricos, fisiológicos e bioquímicos (ASSIS; MENDEZ, 1989; SOUZA et al., 2008). Conforme Souza et al. (2008) alterações na radiação solar levam à alteração de temperatura superficial, o que está ligada à mudanças fenológicas de algumas espécies (MARTIN et al., 2007). Além disso, a Rg também é importante na ativação enzimática, como a ativação da rubisco e a ferrodoxina (CASAROLI et al., 2007).

O monitoramento das variáveis microclimáticas pode servir de subsídio para a execução de atividades agrícolas, pois através do conhecimento do comportamento dessas variáveis pode-se planejar as atividades, a fim de diminuir as percas causadas por intempéries climáticas (SILVA et al., 2005) e aumentar a qualidade do produto final (ROMANI, 2010). Segundo Virgens Filho (2013) o cultivo de espécies vegetais é afetado pela variabilidade climática; as variáveis micrometeorológicas proporcionadas pelos diversos ambientes, podem influenciar na qualidade, produtividade e sanidade de determinadas culturas, podendo aumentar ou reduzir essas características (GUISELINI et al., 2010).

Diante do exposto, objetivou-se monitorar e comparar as variáveis micrometeorológicas, temperatura, umidade relativa e radiação solar global, em cinco ambientes protegidos, durante o inverno, em Cassilândia - MS, localizada na região Centro-Oeste do Brasil.

\section{Material e Métodos}

A pesquisa foi conduzida na Universidade Estadual de Mato Grosso do Sul -UEMS, Unidade Universitária de Cassilândia, localizada na latitude de $19^{\circ} 07^{\prime} 21^{\prime \prime} \mathrm{S}$, longitude de $51^{\circ} 43$ ' 15 " $\mathrm{W}$ e altitude de $516 \mathrm{~m}$. A região apresenta Clima Tropical Chuvoso (Aw) de acordo com a classificação climática de Köppen. Foram utilizados cinco ambientes protegidos, sendo três telados agrícolas e duas estufas agrícolas com dimensões de 18,0 x 8,0 x 4,0 $\mathrm{m}\left(144 \mathrm{~m}^{2}\right)$ com piso coberto por brita

Os ambientes estudados e monitorados foram:

A1.) estufa agrícola coberta com filme de polietileno de baixa densidade (PEBD) difusor de luz e antegotejo, com abertura zenital vedada com tela branca de $30 \%$, com tela preta lateral e frontal de $30 \%$ de sombreamento 
fechada em $90^{\circ}$ e tela termorrefletora aluminizada LuxiNet $^{\circledR}$ móvel de $42 / 50 \%$ sob o filme de PEBD;

A2. estufa agrícola coberta com filme de polietileno de baixa densidade (PEBD) difusor de luz e antegotejo, com abertura zenital vedada com tela branca de $30 \%$, com tela preta lateral e frontal de $30 \%$ de sombreamento fechada em $90^{\circ}$ e tela termorrefletora aluminizada LuxiNet $^{\circledR}$ móvel de 22/30\% sob o filme de PEBD;

A3. telado agrícola vedado com tela termorrefletora aluminizada de $35 \%$ de sombreamento, fechada em 45 graus;

A4. telado agrícola vedado com tela preta de monofilamento de $30 \%$ de sombreamento, fechado em 45 graus;

A5. telado agrícola vedado com tela preta de monofilamento de $18 \%$ de sombreamento, fechado em 45 graus;

A6. ambiente externo aos ambientes protegidos.

Durante o período de inverno (28 de junho a 27 de agosto) foram monitorados e coletados dados diários, de temperatura $\left(\mathrm{T}^{\circ} \mathrm{C}\right)$, umidade relativa do ar $(\mathrm{UR} \%)$ e radiação solar global (RG) a partir de estações meteorológicas modelo E4000 (Irriplus Equipamentos Científicos) instaladas no interior e ao centro de cada ambiente protegido, e os dados externos coletados da estação A742 - Cassilândia (INMET).

As estações E400 realizavam o monitoramento e coleta com fechamento das médias das variáveis a cada hora. Para a temperatura e umidade relativa do ar foram utilizadas médias das 24 horas e para a radiação global foram utilizadas as médias das 9 às 17 horas, ambas com o horário oficial de Brasília. Foram agrupadas as médias de seis em seis dias (repetição), totalizando 10 repetições de cada variável de cada ambiente. Os dados foram submetidos a ANAVA, e as médias comparadas pelo teste de Tukey a $5 \%$ de probabilidade.

\section{Resultados e Discussão}

O período experimental na região de estudo teve temperatura média de $21{ }^{\circ} \mathrm{C}$, umidade relativa de $56 \%$ e radiação global de $501 \mathrm{~W} \mathrm{~m}^{-2}$. Na região Sudeste do Brasil foi encontrada média de $458,9 \mathrm{~W} \mathrm{~m}^{-2}$ de radiação solar global no período de 14-07 a 22-08 de 2000 (inverno), em Campinas- SP (COSTA; LEAL, 2011).

A temperatura máxima durante o inverno na região foi de $35,7^{\circ} \mathrm{C}$, com mínima de $5,5^{\circ} \mathrm{C}$. O mês de agosto apresentou temperatura máxima de $31^{\circ} \mathrm{C}$ e média de $19^{\circ} \mathrm{C}$, com mínima de $5,5^{\circ} \mathrm{C}$, umidade relativa máxima de $92 \%$, média de $56 \%$ e mínima de $28 \%$. O mês de setembro apresentou temperatura máxima de $36{ }^{\circ} \mathrm{C}$ e média de $23{ }^{\circ} \mathrm{C}$, com mínima de $9,7{ }^{\circ} \mathrm{C}$, umidade relativa máxima de $97 \%$, média de $55 \%$ e mínima de $14 \%$. Na região Sul do país, temperaturas máxima de $33,8^{\circ} \mathrm{C}$ e mínima de $5,4{ }^{\circ} \mathrm{C}$ foram encontradas durante o inverno, por Gonçalves-Trevisoli et al. (2017) em Marechal Cândido Rondon, PR. Na região CentroOeste, estado de Mato Grosso, a temperatura média durante o inverno foi de $29,6{ }^{\circ} \mathrm{C}$, máxima de $32,2{ }^{\circ} \mathrm{C}$ e mínima de $26,9^{\circ} \mathrm{C}$ (RAMPAZZO et al., 2014).

Observou-se, no presente estudo que não houve diferença estatística para as variáveis temperatura e umidade relativa do ar nos diferentes ambientes protegidos avaliados (Tabela 1). Andrade et al. (2002) não observaram diferença significativa entre as temperaturas comparando estação seca e úmida nas regiões Norte e Centro-Oeste do país, em áreas de Floresta Amazônica e transição Amazônia-Cerrado.

Conforme Figura 1, observa-se que os ambientes obtiveram temperatura e umidade relativa semelhantes entre si, no período de inverno. O telado de $18 \%$ apresentou temperatura média de $20{ }^{\circ} \mathrm{C}$, UR $62 \%$ e radiação $241 \mathrm{~W} \mathrm{~m}^{-2}$. O telado de $30 \%$ de sombreamento teve temperatura média de $21{ }^{\circ} \mathrm{C}$, UR de $61 \%$ e radiação de $254 \mathrm{~W} \mathrm{~m} \mathrm{~m}^{-2}$. No telado aluminizado de $35 \%$ a temperatura média foi $20{ }^{\circ} \mathrm{C}$, UR $60 \%$ e RG $194 \mathrm{~W} / \mathrm{m}^{2}$. Ambientes com tela preta e ambientes com tela termorrefletora, todos com 30,40 e $50 \%$ de sombreamento reduziram a temperatura dos ambientes, comparadas com a temperatura em campo aberto, em Cáceres, Mato Grosso, região Centro-Oeste, com médias próximas a $30{ }^{\circ} \mathrm{C}$ (SANTOS et al., 2010), onde a tela preta de sombreamento $40 \%$ reduziu em $6 \%$ a temperatura média, em relação ao campo aberto.

Tabela 1. Temperatura, umidade relativa e radiação global em cada ambiente no período de inverno. Cassilândia-MS, 2017.

\begin{tabular}{lccc}
\hline Ambiente & Temperatura & Umidade Relativa & Radiação Global \\
\hline Externo & $20,90 \mathrm{a}$ & $55,92 \mathrm{a}$ & $500,94 \mathrm{a}$ \\
Telado preto 18\% de sombreamento & $20,02 \mathrm{a}$ & $62,06 \mathrm{a}$ & $240,85 \mathrm{~b}$ \\
Telado preto 30\% de sombreamento & $20,94 \mathrm{a}$ & $60,93 \mathrm{a}$ & $253,63 \mathrm{~b}$ \\
Telado prata 35\% de sombreamento & $20,19 \mathrm{a}$ & $59,74 \mathrm{a}$ & $193,71 \mathrm{bc}$ \\
Estufa agrícola 22/30\% de sombreamento & $20,62 \mathrm{a}$ & $57,28 \mathrm{a}$ & $196,3 \mathrm{bc}$ \\
Estufa agrícola 42/50\% de sombreamento & $20,63 \mathrm{a}$ & $58,74 \mathrm{a}$ & $146,63 \mathrm{c}$
\end{tabular}

Médias seguidas de mesma letra na coluna não diferem entre si pelo teste Tukey a 5\% de probabilidade. 
$\mathrm{Na}$ estufa de 22 a $30 \%$ de sombreamento a temperatura média foi de $21^{\circ} \mathrm{C}$, UR de $57 \%$ e RG de $197 \mathrm{~W} / \mathrm{m}^{2}$. Na estufa de 42 a $50 \%$ de sombreamento a temperatura média foi $21^{\circ} \mathrm{C}$, UR $59 \%$ e RG $147 \mathrm{~W} \mathrm{~m}^{-2}$. Esses resultados corroboram com os de Lulu et al. (2005) que testaram o cultivo de uvas com cobertura plástica de PEBD e sem filme plástico, e verificaram menor radiação disponível sob o filme de polietileno, reduzindo assim danos aos frutos e obtendo maior massa dos cachos. Conforme resultados de Costa et al. (2012) a temperatura média ficou próxima a $33^{\circ} \mathrm{C}$ e UR em $56 \%$, em ambiente do tipo estufa coberta com filme polietileno de $150 \mu \mathrm{m}$, com difusor de luz, tela termorrefletora de $50 \%$ de sombreamento sob o filme e fechamento com tela de monofilamento $50 \%$.

No presente estudo verificou-se diferença entre a radiação global obtida nos diferentes ambientes, como pode ser observado na (Tabela 1 ), onde observa-se que a estufa agrícola de $42 / 50 \%$ de sombreamento proporcionou menor radiação global que no ambiente externo, telado $18 \%$ e telado $30 \%$, não diferindo do telado aluminizado de $35 \%$ e da estufa agrícola de $22 / 30 \%$. Guiselini et al. (2010) verificaram menor radiação solar global no interior dos ambientes protegidos projetados com filme de PEBD e malha termorrefletora de $50 \%$ de sombreamento, comparados ao ambiente externo. A menor disponibilidade de radiação em um ambiente pode ser importante quando se cultiva algumas espécies vegetais. César et al. (2014) observaram que plantas de amendoim-do-campo submetidas à radiação solar intensa apresentaram menores valores de massa seca.

Na região Centro-Oeste, estado de Mato Grosso, Rampazzo et al. (2014) revelaram que ambientes telados de 30,40 e $50 \%$ de sombreamento e ambientes com tela termorrefletora de 30,40 e $50 \%$, comparados ao ambiente externo proporcionam menores temperaturas médias e maior umidade relativa média do ar. Em Ilha Solteira, Andrade et al. (2011) mostram que as temperaturas máximas foram maiores em estufa coberta com polietileno convencional, comparadas à estufa coberta com filme térmico difusor de luz.

A comparação de cinco ambientes protegidos constituídos por malha vermelha de 71 a $75 \%$, malha vermelha de 51 a $55 \%$, malha plástica preta com 50 a $55 \%$, malha vermelha de 28 a $32 \%$ de sombreamento e sem malha, todos com cobertura de filme de PEBD, mostrou que durante o inverno a temperatura foi menor e UR maior no ambiente com malha vermelha de 71 a $75 \%$ de sombreamento (SCARANARI et al., 2008).

A Figura 2 compara a radiação solar no interior dos ambientes à radiação solar externa. A radiação global no interior da estufa 42/50\% (E42) não diferiu da radiação da estufa 22/30\% (E22) e do telado aluminizado 35\% (T35) (Figura 2). Nestes ambientes foram registradas porcentagens de radiações de 29, 39 e 39\% da radiação solar global externo, respectivamente, ou seja, houve redução em 71 e $61 \%$ da radiação global externa. Nos telados de 18 (T18) e 30\% (T30) de sombreamento, houve diminuíram em 52 e $49 \%$ da radiação global externa, respectivamente (Figura 2). Conforme Guiselini et al. (2010) malhas termorrefletoras promovem maiores temperaturas no inverno, devido a conservação de energia. Em Cáceres, estado de Mato Grosso, Santos et al. (2010) verificaram que telas termorrefletoras de $30 \%$ de sombreamento reduziram em $35 \%$ a luminosidade e telas termorrefletoras de $40 \%$ reduziram em $50 \%$ a chegada de luz no ambiente telado.

No Sudeste, em Rio das Pedras, SP, no período de agosto de 2011 a janeiro de 2010, Ferrari e Leal (2015) verificaram que o uso de tela termorrefletora em ambiente do tipo capela, coberto com filme de PEDB, com manejo de abertura e fechamento da tela reduziu em $37 \%$ a radiação global, com valor de $260,7 \mathrm{~W} \mathrm{~m}^{-2}$ no ambiente com tela e $415,2 \mathrm{~W} \mathrm{~m}^{-2}$ no ambiente sem tela. No presente estudo as telas termorrefletoras foram de uso fixo, sem manejo de abertura e fechamento.

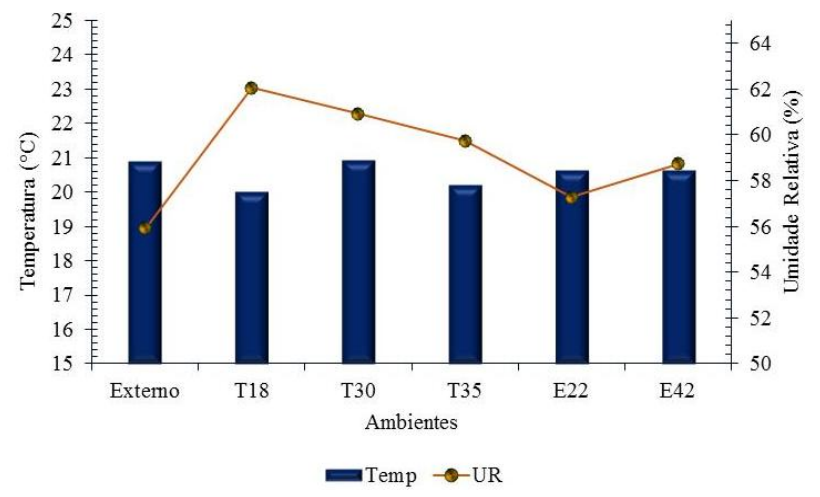

Figura 1. Temperatura e Umidade relativa nos diferentes ambientes avaliados, no inverno, em Cassilândia - MS.

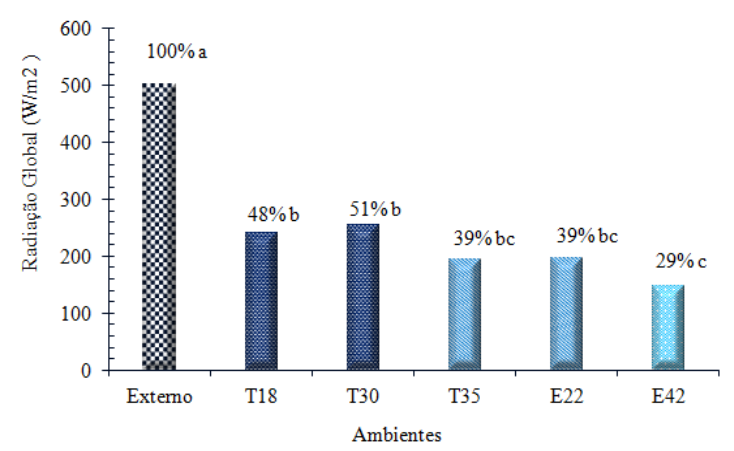

Figura 2. Porcentagem de Radiação Global ofertada no interior de cada ambiente protegido, no inverno em relação à radiação externa. Cassilândia-MS, 2017.

No período verão-outono em Pelotas-RS, constatouse que a radiação global no interior de estufa coberta com filme PEBD foi menor que no exterior, representando $76 \%$ da RG externa, sendo que em dias 
nublados a atenuação da RG pelo filme plástico é reduzida (BECKMANN et al.,2006). Scaranari et al. (2008) verificaram que ambiente coberto com filme de PEBD com malha vermelha de 71 a $75 \%$, malha vermelha de 51 a $55 \%$, malha plástica preta com 50 a $55 \%$, malha vermelha de 28 a $32 \%$ de sombreamento, proporcionaram maior redução da radiação global interna, comparada ao ambiente coberto apenas com filme de PEBD sem malha de sombreamento.

Na região Sudeste do Brasil, Andrade et al. (2011) verificaram menor disponibilidade de RG em ambiente coberto com filme térmico difusor de luz, que em ambiente coberto com filme de polietileno convencional, no entanto, ambos com menor RG comparada a céu aberto, nas condições climáticas de Ilha Solteira - SP.

No período primavera-verão, Radin et al. (2003) citam que a radiação solar global é maior que no período verão-outono. Andrade et al. (2002) estudaram o comportamento das variáveis micrometeorológicas em Rondônia, região Norte e Mato Grosso, região CentroOeste do Brasil, verificando que durante a estação seca (junho, julho e agosto) em Rebio Jaru - Rondônia, a radiação solar incidente foi superior e a UR maior nos meses de dezembro, janeiro e fevereiro (estação úmida); em Mato Grosso, na fazenda Maracaí a maior radiação solar incidente foi observada na estação úmida.

A intensidade de radiação pode modificar a estrutura das folhas, os cloroplastos e os pigmentos (RIGHI et al., 2006), por isso deve-se considerar que a menor radiação ofertada por um ambiente, nem sempre acarretará em comportamento positivo das culturas produzidas nesses ambientes, pois a radiação fotossintética ativa (RFA) é componente da radiação solar global. Ferrari e Leal (2015) citam que níveis de RFA abaixo do ponto de saturação limitam a fotossíntese, diminuindo a assimilação de açúcares e refletindo em menor qualidade e produtividade das culturas; ao contrário, níveis de RFA acima do ponto de saturação podem ocasionar diminuição da taxa fotossintética devido à menor assimilação de $\mathrm{CO}_{2}$, maior transpiração e temperatura do vegetal, ou seja, acima do ponto ótimo ocorre a saturação das folhas superiores (RADIN et al. 2003). Ressalta-se que esse ponto de saturação está relacionado ao metabolismo de cada espécie e a disponibilidade de fitocromo.

Dados da FAO (1990) mostram que para espécies de alta saturação de radiação, valores de radiação abaixo de $8,4 \mathrm{MJ} \mathrm{m}^{2} \mathrm{~d}^{1}$ ocasionariam crescimento inadequado das plantas. De outra forma, plantas de tabaco possuem alto ponto de saturação luminosa $\left(1200 \mu \mathrm{mol} \mathrm{m} \mathrm{m}^{-2} \mathrm{~s}^{-1}\right) \mathrm{em}$ concentrações de $\mathrm{CO}_{2}$ ambiente (JIANG et al., 1994). Nas mesmas condições plantas de Arabidopsis apresentam ponto de saturação luminosa em $600 \mu \mathrm{mol}$ $\mathrm{m}^{-2} \mathrm{~s}^{-1}$ (SALVUCCI; OGREN, 1986).
Ressalta-se que as propriedades físicas dos materiais componentes do ambiente protegido mudam com o tempo de uso, como observado por Ferrari e Leal (2015), em que telas termorrefletoras de $50 \%$ de sombreamento sem uso apresentaram 50\% de transmitância, enquanto após o uso esse valor caiu para $43 \%$, desta forma, o fornecimento de radiação difusa é reduzido. As telas utilizadas nesse estudo apresentam aproximadamente um ano de uso

\section{Conclusões}

Durante o inverno não houve diferença no comportamento das temperaturas e umidades relativas nos ambientes protegidos e externo.

A radiação solar global ofertada foi menor quanto maior o sombreamento dos ambientes protegidos utilizados. A região apresentou temperatura média de 21 ${ }^{\circ} \mathrm{C}$, umidade relativa de $56 \%$ e radiação global de $501 \mathrm{~W}$ $\mathrm{m}^{-2}$ durante o período de inverno.

As maiores e menores reduções da radiação solar externa ocorreram, respectivamente, na estufa coberta com filme de PEBD com tela termorrefletora de 42-50 $\%$ de sombreamento sob o filme, com $71 \%$ e no telado de $30 \%$ de sombreamento com $49 \%$.

\section{Agradecimentos}

À CAPES e à FUNDECT pelo apoio financeiro e pela concessão de bolsas. Ao Programa de Apoio a Núcleos Emergentes (PRONEM-MS) Edital Chamada FUNDECT/CNPq $\mathrm{N}^{\circ}$ 15/2014; TERMO DE OUTORGA: 080/2015 SIAFEM: 024367. A FUNDECT/PPP (Programa Primeiros Projetos) Edital 05/2011, Proc. No 23/200.647/2012, TERMO DE OUTORGA: 0152/12 SIAFEM: 020865. A FUNDECT/UEMS n 25/2015 - Apoio à Graduação e Pós-graduação na UEMS (Projeto de Apoio ao Programa de Pós-Graduação em Agronomia - Área de Concentração: Sustentabilidade na Agricultura).

\section{Referências Bibliográficas}

ANDRADE, N. L. R.; AGUIAR, R. G.; SANCHES, L.; ALVES, D. C. R. F.; NOGUEIRA. J. S. Partição do saldo de radiação em áreas de floresta amazônica e floresta de transição amazônia-cerrado. Revista Brasileira de Meteorologia, São José dos Campos-SP, v. 24, n. 3, p. 346-355, 2009.

ANDRADE, J. W. S.; FARIAS JÚNIOR, M.; SOUSA, M. A.; ROCHA, A. C. Utilização de diferentes filmes plásticos como cobertura de abrigos para cultivo protegido. Acta Scientiarum Agronomy, Maringá-PR, v. 33, n. 3, p. 437-443, 2011

ASSIS, F. N.; MENDEZ, M. E. G. Relação entre radiação fotossinteticamente ativa e radiação global. Pesquisa 
Agropecuária Brasileira, Brasília-DF, v. 24, n. 7, p. 797800, 1989.

BECKMANN, M. Z.; DUARTE, G. R. B.; PAULA, V. A.; MENDEZ, M. E. G.; PEIL, R. M. N. Radiação solar em ambiente protegido cultivado com tomateiro nas estações verão-outono do Rio Grande do Sul. Ciência Rural, Santa Maria-RS, v. 36, n. 1, p. 86-92, 2006.

CARDOSO, L.S.; BERGAMASCHI, H.; COMIRAN, F.; CHAVARIA, G.; MARODIN, G. A. B.; DAMALGO, G. A.; SANTOS, H. P.; MANDELLI, F. Alterações micrometeorológicas em vinhedos pelo uso de coberturas de plástico. Pesquisa Agropecuária Brasileira, Brasília-DF, v. 43 , n. 4, p. 441-447, 2008 .

CARON, B. O.; SOUZA, V. Q.; CANTARELLI, E. B.; MANFON, P. A.; BEHLING, A.; ELOY, E. Crescimento em viveiro de mudas de Schizolobium parahyba (Vell.) S. F. Blake. submetidas a níveis de sombreamento. Ciência Florestal, Santa Maria-RS, v. 20, n. 4, p. 683-689, 2010.

CÉSAR, F. R. C. F.; MATSUMOTO, S. N.; VIANA, A. E. S.; BONFIM, J. A. Crescimento inicial e qualidade de mudas de Pterogyne nitens Tull. conduzidas sob diferentes níveis de restrição luminosa artificial. Ciência Florestal, Santa MariaRS, v. 24, n. 2, p. 357-366, 2014.

CHAVARRIA, G; SÔNEGO, H. P.; MARODIN, O. R.; BERGAMASCHI, G. A. B.; CARDOSO, H.; SILVEIRA, L. Incidência de doenças e necessidade de controle em cultivo protegido de videira. Revista Brasileira de Fruticultura, Jaboticabal-SP, v. 29, n. 3, p. 477-482, 2007.

CHAVARIA, G.; CARDOSO, L. S.; BERGAMASCHI, H.; SANTOS, H. P.; MANDELLI, F.; MARODIN, G. A. B. Microclima de vinhedos sob cultivo protegido. Ciência Rural, Santa Maria-RS, v. 39, n. 7, p. 2029-2034, 2009.

COSTA, E.; LEAL, P. M. Medidas radiométricas em casas de vegetação com cobertura plástica na região de Campinas-SP. Engenharia Agrícola, Jaboticabal-SP, v. 31, n. 3, p. 448-457, 2011.

COSTA, E.; MESQUITA, V. A. G.; LEAL, P. A. M.; FERNANDES, C. D.; ABOI, A. R. Formação de mudas de mamão em ambientes de cultivo protegido em diferentes substratos. Ceres, Viçosa-MG, v. 57, n. 5, p. 679-685, 2010.

CUNHA, A. R.; ESCOBEDO, J. F.; KLOSOWSKI, E. S. Estimativa do fluxo de calor latente pelo balanço de energia em cultivo protegido de pimentão. Pesquisa Agropecuária Brasileira, Brasília-DF, v. 37, n. 6, p. 735-743, 2002.

FAO. FOOD AND AGRICULTURE ORGANIZATION OF THE UNITED NATIONS. Protected cultivation in the Mediterranean climate. Roma: FAO, 1990. 313 . (Plant Production and Protection Paper, 90).

FERRARI, D. L.; LEAL, P. A. M. Uso de tela termorrefletora em ambientes protegidos para cultivo do tomateiro. Engenharia Agrícola, Jaboticabal-SP, v. 35, n. 2, p. 180-191, 2015.

GONÇALVES-TREVISOLI, E. D. V.; MENDONÇA, H. F. C.; DILDEY, O. D. F.; DARTORA, J.; RISSATO, B. B.; COLTRO-RONCATO, S.; KLOSOWSKI, E. S.; TSUTSUMI, C. Y.; ECHER, M. M. Ambiência e desempenho produtivo de rúcula cultivada em diferentes espaçamentos. Scientia Agraria Paranaensis, Marechal Cândido Rondon-PR, v. 16, n. 2, p. 230-236, 2017.

GUISELINI, C.; SENTELHAS, P. C.; PANDORFI, H.; HOLCMAN, E. Manejo da cobertura de ambientes protegidos: Radiação solar e seus efeitos na produção de gérbera. Revista Brasileira de Engenharia Agrícola e Ambiental, Campina Grande-PB, v. 14, n. 6, p. 645-652, 2010.

JIANG, C. Z.; QUICK, W. P.; ALRED, R.; KLIEBENSTEIN, D.; RODERMEL, S. R. Antisense RNA inibition of Rubisco activase expression. The Plant Journal, Washington, v. 5, n. 6, p. 787-798, 1994

LULU, J.; CASTRO, J. V.; PEDRO JÚNIOR, M. J. Efeito do microclima na qualidade da uva de mesa 'romana' (A 1105) cultivadas sob cobertura plástica. Revista Brasileira de Fruticultura, Jaboticabal-SP, v. 27, n. 3, p. 422-425, 2005.

MARTIN, T. N.; STORCK, L.; DOURADO NETO, D. Simulação estocástica da radiação fotossinteticamente ativa e da temperatura do ar por diferentes métodos. Pesquisa Agropecuária Brasileira, Brasília-DF, v. 42, n. 9, p. 1211 1219, 2007.

OLIVEIRA, A. B.; MEDEIROS FILHA, S.; BEZERRA, A. M. E.; BRUNO, R. L. A. Emergência de plântulas de Copernia hospital Martins em função do tamanho da semente, do substrato e ambiente. Revista Brasileira de Sementes, Londrina-PR, v. 31, n. 1, p.281-287, 2009.

RADIN, B.; BERGAMASCHI, H.; REISSER JUNIOR, C.; BARNI, N. A.; MATZENAUER, R.; DIDONÉ, I. A. Eficiência de uso da radiação fotossinteticamente atva pela cultura do tomateiro em diferentes ambientes. Pesquisa Agropecuária Brasileira, Brasília-DF, v. 38, n. 9, p. 1017 1023, 2003.

RAMPAZZO, R.; SEABRA JUNIOR, S.; NUNES, M. C. M.; NEVES, S. M. A.; FERREIRA, R. F. Eficiência de telas termorrefletoras e de sombreamento em ambiente protegido tipo telado sob temperaturas elevadas. Engenharia na Agricultura, Viçosa-MG, v. 22, n. 1, p.33-42, 2014.

ROMANINI, C. E. B. Desenvolvimento e simulação de um sistema avançado de controle ambiental em cultivo protegido. Revista Brasileira de Engenharia Agrícola Ambiental, Campina Grande-PB, v. 14, n. 11, p. 1194-1201, 2010.

SALVUCCI, M. E.; OGREN, W. L. The mechanism of Rubisco activase: Insights from studies of the properties and structure of the enzyme. Photosynthesis Research, Boston, v. 47, n. 1, p. 1-11, 1996.

SANTOS, L. L.; SEABRA JUNIOR, S.; NUNES, M. C. M. Luminosiade, temperatura do ar e do solo em ambientes de cultivo protegido. Revista de Ciências Agro-Ambientais, Alta Floresta-MT, v. 8, n. 1, p. 83- 93, 2010.

SCARANARI, C.; LEAL, P. A. M.; PELLEGRINO, G. Q. Estudo de simulação de mivroclima em casas de vegetação visando à aclimatação de mudas micropropagadas de bananeira cv Grande Naine. Revista Brasileira de Fruticultura, Jaboticabal-SP, v. 30, n. 4, p. 1001-1008, 2008.

SILVA, J. B.; LLOPART, M. P.; BOIASKI, N. Temperatura máxima do ar em Pelotas-RS - Tabelas de probabilidades em 
escalas de tempo pentadal. Revista Brasileira de Meteorologia, São José dos Campos-SP, v. 20, n. 2, p. 267276, 2005.

SOUSA, J. W.; MARTINS, D.; CUNHA, A. R.; ESCOBEDO, J. F.; GALVANI, E. Alterações da temperatura e umidade relativa do ar em ambiente protegido com cobertura de polietileno difusor de luz. Revista Brasileira de Agrometereologia, Santa Maria-RS, v. 10, n. 1, p. 1-9, 2002.
SOUZA, J. D.; SILVA, B. B.; CEBALLOS, J. C. Estimativa da radiação solar global à superfície usando um modelo estocástico: caso sem nuvens. Revista Brasileira de Geofísica, Rio de Janeiro-RJ, v. 26, n. 1, p. 31-44, 2008.

VIRGENS FILHO, J. S.; OLIVEIRA, R. B. I; LEITE, M. L.; TSUKAHARA, R. Y. Desempenho dos modelos CLIGEN, LARS-WG e PGECLIMA_R na simulação de séries diárias de temperatura máxima do ar para localidades do estado do Paraná. Engenharia Agrícola, Jaboticabal-SP, v.33, n. 3, p. 538-547, 2013. 